ISSN 0103-9954

\title{
RELAÇÕES SOLO-VEGETAÇÃO EM "ILHAS" FLORESTAIS E SAVANAS ADJACENTES, NO NORDESTE DE RORAIMA
}

\author{
SOIL-VEGETATION RELATIONSHIP IN FOREST ISLANDS AND ADJACENT SAVANNA AT THE \\ NORTHEAST RORAIMA, AMAZONIA
}

\author{
Keily Katiany Almeida Feitosa ${ }^{1}$ José Frutuoso do Vale Júnior ${ }^{2}$ \\ Carlos Ernesto Gonçalves Reynaud Schaefer ${ }^{3}$ Maria Ivonilde Leitão de Sousa ${ }^{4}$ Pedro Paulo Ramos \\ Ribeiro Nascimento ${ }^{5}$
}

\section{RESUMO}

O estudo de solos em ilhas florestais inseridas em áreas de domínio de savanas é fundamental para compreender os processos de formação da paisagem. Este trabalho caracterizou propriedades morfológicas, físicas e químicas de solos em quatro fragmentos naturais de florestas de ocorrência no mosaico savanafloresta em Roraima, norte da Amazônia. O método consistiu em transectos atravessando as ilhas nos sentidos leste-oeste e norte-sul, onde foram abertas cinco trincheiras para a coleta de amostras e estudos de solos. Nas áreas de savana contíguas a cada ilha foram estabelecidos transectos de $100 \mathrm{~m}$ de comprimento e abertas cinco trincheiras equidistantes para caracterização química e física do solo comparativa. Os Latossolos foram as classes de solos predominantes nas quatro ilhas investigadas, seguida de Argissolos e Plintossolos, todos predominantemente oligotróficos (distróficos, de baixa CTC, ácidos). Condições químicas e físicas melhores foram verificadas nos solos das ilhas florestais em relação às áreas de savana circundantes, numa mesma classe de solo. Assim, embora a classe de solo não tenha variado entre diferentes fitofisionomias em um dado gradiente, características químicas e físicas específicas variaram e podem exercer influência positiva no estabelecimento de vegetação florestada. Embora florestas e savanas ocorram lado a lado, em mosaico, o clima atual com longa estação seca é concordante com a existência da savana em relevo plano e a ocorrência das ilhas florestais parece condicionada a variações físico-químicas sutis dos solos, sem necessidade de invocar uma relação com oscilações paleoclimáticas. Estudos mais aprofundados posteriores poderão testar a hipótese de contração ou expansão florestal durante o Quaternário, buscando evidências de que tais ilhas possam representar relíquias paleoclimáticas imersas em domínio savânico. Palavras-chave: mudanças climáticas e solos; solos da Amazônia; paleoecologia da Amazônia; ecologia de solos.

\section{ABSTRACT}

Studies on soils of forest islands within the savanna domain are key for understanding processes of landscape formation and evolution. We characterized the morphological, physical and chemical properties of soils

1 Engenheira Agrônoma, MSc., Engenheira Agrônoma da Secretária de Agricultura, Pecuária e Abastecimento de Estado de Roraima, Rua Ademário Santos, 762, Qd. 38, Caimbé II, CEP 69312-168, Boa Vista (RR), Brasil. keilyk@uol.com.br

2 Engenheiro Agrônomo, Dr., Professor Associado do Departamento de Solos e Engenharia Agrícola, Universidade Federal de Roraima, Campus Cauamé, BR 174, Km 12, Bairro Monte Cristo, CEP 69300-000, Boa Vista (RR), Brasil.valejr51@gmail.com.br

3 Engenheiro Agrônomo, PhD., Professor Associado do Departamento de Solos, Universidade Federal de Viçosa, Av. pH Rolfs, s/n, CEP 36571-000, Viçosa (MG), Brasil. carlos.schaefer@ufv.br

4 Engenheira Agrônoma, MSc., Agrônoma da Secretária Municipal de Gestão Ambiental e Assuntos Indígenas (SMGA), Rua Desembargador Francisco Murilo Pinto, 94, Bairro Caçari, CEP 69312-168, Boa Vista (RR), Brasil. ivonildeufrr@gmail.com.br

5 Graduando em Agronomia, Universidade Federal de Roraima, Rua das Palmeiras 86, Pricumã, CEP 69309-600, Boa Vista (RR), Brasil. Bolsista de iniciação científica. pedonpaulo@hotmail.com

Recebido para publicação em 29/04/2013 e aceito em 30/01/2014 
at four different forest fragments that occur in the savanna-forest mosaic of northeastern Roraima, north Amazonia. The methodology was based on transects crossing the entire island, from east-west and northsouth direction, digging up five soil profiles for sampling and classification. In addition, the neighboring savannas were also sampled following the same strategy, at $100 \mathrm{~m}$ long transects departing from the border, allowing comparisons to be made. Latosols were the dominant soil class in all four islands, followed by Ultisols and Plinthosols. All soils were dystric, with low CEC and acid. Better chemical and physical conditions were observed in forested soils compared with surrounding savannas, in a given soil class. Thus, in spite of no variation on soil class at different phytophysionomies at a given gradient, specific chemical and physical attributes were significantly varied, exerting a positive effect for the establishment of forest vegetation. Despite their occurrence side-by-side in the savanna- forest mosaic, the present -day climate agrees with the existence of savanna in the flat landforms, whereas forest islands are conditioned by subtle, yet significant, soil physico-chemical variations, with no need to invoke any paleoclimate for explaining this relationship. Further in depth studies may contribute for testing the hypothesis that Quaternary shifts of the expansion and contraction of forest may represent paleoclimate relicts isolated within the savanna domain.

Keywords: climate changes and soils; amazon soils; amazon paleoecology; soil ecology.

\section{INTRODUÇAO}

As manchas ou encraves de cerrado estão dispersas pelo Bioma Amazônia e encontram-se inseridas, principalmente, nos estados do Amapá, Amazonas, Pará e Roraima, sendo conhecidas regionalmente como savanas amazônicas (MIRANDA et al., 2003). As Savanas de Roraima ocupam $17 \%$ do Estado e representam a maior área contínua de savanas no bioma Amazônia, ocupando quase todo o setor centro-leste e nordeste do estado em uma área aproximada de $43.000 \mathrm{~km}^{2}$ (BARBOSA e CAMPOS, 2011).

As áreas de savanas roraimenses se apresentam em forma de mosaico, formado por extensa superfície aplainada revestida por vegetação graminosa/arbustiva, interrompido abruptamente por ilhas florestais. "Distribuídas pelas savanas encontram-se outras formações vegetais distintas como pequenas ilhas de florestas, que são fragmentos florestais naturais, isolados, encontrados em áreas abertas das zonas de contato savana-floresta dos Neotrópicos (HUBER et al., 2006), geralmente estacionais, muito comuns principalmente na região da Formação Boa Vista." (BARBOSA e CAMPOS, 2011).

A causa da coexistência de Savanas e Florestas Estacionais Semideciduais em uma dada região, sob um mesmo clima, tem sido investigada e alguns estudos têm buscado explicações para sua ocorrência. Para Mayle e Power (2008), estas formações naturais foram originadas pelo mecanismo de expansão e retração de grandes domínios de vegetação ocorridos por ocasião da atuação de climas alternantes ao longo do Quaternário. Portanto, são considerados relíquias paleoclimáticas, de épocas em que um maciço florestal pretérito, mais amplo, se estendia além de seus limites atuais.

Embora climas mais úmidos possam, em tese, favorecer a expansão florestal, outros fatores abióticos, como a recorrência do fogo em relevo extensamente plano e aberto, combinado a solos extremamente distróficos e coesos, são condições favoráveis à permanência de savana em Roraima (SCHAEFER, 1997; SCHAEFER \& DALRYMPLE, 1995). Como consequência, as savanas de Roraima floristicamente pobres com espécies adaptadas ao fogo e ao hidromorfismo (SCHAEFER et al., 1994) e fraco desenvolvimento do estrato arbustivo e arbóreo. Além disso, o nordeste de Roraima representa uma zona de tensão ecológica, onde variações climáticas sazonais determinam grandes transformações ecológicas, no tempo e no espaço (SCHAEFER, 1997; BENEDETTI et al., 2011).

Diferente da Floresta Estacional existente no planalto central do Brasil, reconhecidas por abrigarem uma diversidade de plantas muito específica (FELFILI et al., 2007; OLIVEIRAFILHO et al., 2006), os remanescentes florestais da Amazônia têm sido negligenciados. Na grande área de savana do nordeste de Roraima (regionalmente chamada de "lavrado"), tais fragmentos estão estabelecidos ao longo do limite com a floresta contínua (BARBOSA e CAMPOS, 2011).

Entretanto, os fragmentos florestais em 
Roraima são perturbados por ação antrópica, do mesmo modo que as bordas da floresta contínua com a savana. Os fragmentos de maior área física (> 10 ha) são mais utilizados para agricultura de subsistência (desmatamento), mas extração seletiva de madeira (exploração econômica), conforto térmico do gado (pisoteio do sub-bosque) e ação do fogo (susceptibilidade) são perturbações comuns. Desta forma, distúrbios antropogênicos e dimensão dos fragmentos também são variáveis que podem influenciar na riqueza e diversidade de espécies, pois tendem a acarretar alteração no microclima e permitir maior vulnerabilidade a secas e fogos (LAURANCE et al., 2000; ROSS et al., 2002; FERREIRA et al., 2002).

Segundo alguns autores, o fator ecológico preponderante na distribuição dos tipos de savana, dentro de seu próprio limite fitogeográfico é o solo (TOPPA, 2004; NERI et al., 2012) que verificaram um gradiente de fertilidade acompanhando o gradiente fisionômico da vegetação de savana, exercendo influência na composição florística e estrutura da vegetação.

Moreno e Schiavini (2001) estudaram um gradiente florestal em Minas Gerais, revelando influência positiva da concentração de cálcio, potássio, fósforo, alumínio, saturação por alumínio, saturação por bases e matéria orgânica na diferenciação entre as fitofisionomias estudadas. Rossi et al. (2005) verificaram que Latossolos de textura média e com alta saturação por alumínio estão associados à vegetação de cerrado, enquanto solos com maiores teores de matéria orgânica e nutrientes em superfície ocorrem associados à floresta.

Já Martins et al. (2006) e Campos et al. (2012), estudando os atributos dos solos sob vegetação campestre e floresta em Humaitá, no Estado do Amazonas, constataram que os solos sob vegetação campestre e floresta possuem atributos químicos e mineralógicos semelhantes e que o aparecimento da vegetação de florestal é favorecido por solo com maior profundidade e melhor drenagem.

Com base nas referências acima citadas, constata-se que vários estudos têm buscado compreender os fatores que determinam a existência de mosaicos formados por savana e florestas sob um mesmo clima. Em Roraima, esse ecossistema tem despertado o interesse de vários pesquisadores. No entanto, apesar de já haver alguns estudos enfocando a savana e solos associados (e.g. SCHAEFER et al.,
1993; 1994; MIRANDA et al., 2003; BARROS et al., 2009; BENEDETTI et al., 2011), são necessários trabalhos que enfoquem a correlação entre os atributos dos solos e a ocorrência de ilhas florestais no ambiente de savana.

Considerando o limitado conhecimento sobre as interações entre as comunidades vegetais e os fatores abióticos que sustentam os fragmentos florestais do Nordeste de Roraima e sua importância como refúgio para espécies da fauna e da flora, o objetivo deste estudo foi caracterizar e classificar os solos sob ilhas florestais e as savanas nos quais estão inclusas, enfatizando as relações solo-vegetação, ao longo de gradientes.

\section{MATERIAL E MÉTODOS}

$\mathrm{O}$ estudo foi conduzido em quatro ilhas florestais (IF) e em savana (SV) adjacente, no município de Boa Vista, nordeste do estado de Roraima. Estão localizadas à margem esquerda da BR 174 no sentido Boa Vista - Pacaraima, a 35 $\mathrm{km}$ da sede do município, na área do Projeto de Assentamento Nova Amazônia 1 (PANA 1).

A ilha florestal 1 (IF1) abrange uma área com cerca de 46,41 ha e está situada sob as coordenadas em projeção UTM 200741641 norte e 0342673 leste. A ilha florestal 2 (IF2) tem uma área total de 13,30 ha, sob as coordenadas UTM 20 0737873 norte e 0340295 leste. A Ilha florestal 3 (IF3) tem uma área total de 7,57 ha, localiza-se à margem esquerda da BR 342, sob as coordenadas UTM 20741371 norte e 0344137 leste. A ilha florestal 4 (IF4) tem uma área total de 7,45 ha, sob as coordenadas UTM 20741371 norte e 0344137 leste.

De acordo com a classificação de Köppen, o clima da região é Awi. A cobertura vegetal das ilhas é de floresta estacional semidecidual, circundada por savana parque e savana gramíneo-lenhosa (BARBOSA, 1997). Para cada ilha florestal foi estabelecido um transecto de $100 \mathrm{~m}$ de comprimento, partindo do centro no sentido norte - sul e leste oeste. Ao longo do transecto foram abertas cinco trincheiras equidistantes. Para cada classe de solo identificada, foi aberta uma trincheira de $200 \mathrm{~cm}$ de profundidade, representando o solo típico (modal). Nos pontos de amostragem nos quais já havia um perfil modal, as trincheiras foram até $40 \mathrm{~cm}$ de profundidade. A descrição morfológica foi realizada segundo o manual de descrição e coleta de solos no campo (SANTOS et al., 2005). A cor do solo 
foi determinada em amostras de solo úmido, em campo, utilizando-se a caderneta de Munsell (2009) e a classificação foi conforme o Sistema Brasileiro de Classificação de Solos (EMBRAPA, 2013).

Nas trincheiras foram coletadas amostras indeformadas e deformadas de solo nas profundidades de $0-10 \mathrm{~cm}, 10-20 \mathrm{~cm}$ e de $20-40$ $\mathrm{cm}$. As amostras deformadas foram destinadas para análises físicas e químicas e as indeformadas, foram acondicionadas em latas de alumínios para estudo de densidade do solo, pelo método do anel volumétrico (EMBRAPA, 1997), utilizando anéis com volume de $50 \mathrm{~cm}^{3}$, com cinco repetições nas profundidades de $0-10 \mathrm{~cm}, 10-20 \mathrm{~cm}$ e de $20-40 \mathrm{~cm}$ e determinação do teor de umidade gravimétrica das amostras. Para avaliação física e química comparativa dos solos sob savana e floresta foi estabelecido transectos contornando as formações vegetais, a uma distância de $100 \mathrm{~m}$ de sua borda, para minimizar os efeitos da transição.

O material coletado no campo foi devidamente acondicionado em sacos plásticos e em latas de alumínio. Posteriormente foram conduzidos ao Laboratório do Núcleo de Recursos Naturais NUREN, da Universidade Federal de Roraima no Campus Cauamé e para o Laboratório de solos da EMBRAPA-RR, para a realização das análises.

A resistência mecânica do solo à penetração a campo, foi medida com penetrômetro de pressão, nas profundidades de $0-10$, de $10-20$ e de 20 a 40 $\mathrm{cm}$, com cinco repetições em cada tipo de solo.

A composição granulométrica foi determinada após dispersão da TFSA com $\mathrm{NaOH}$ $1 \mathrm{~mol}^{-1}$ e agitação; a fração areia foi obtida por peneiramento úmido, a argila pelo método de Bouyocus e o silte por diferença (EMBRAPA, 1997).

$\mathrm{O}$ pH em água foi determinado na relação solo: água de 1:2,5; $\mathrm{Al}, \mathrm{Ca}$ e $\mathrm{Mg}$ trocáveis foram extraídos com $\mathrm{KCl} 1 \mathrm{~N}, \mathrm{~K}$ e $\mathrm{P}$ por Mehlich-1 e $\mathrm{H}+\mathrm{Al}$ com solução de acetato de cálcio $1 \mathrm{~N}$ a $\mathrm{pH}$ 7,0 (EMBRAPA, 1997). O carbono orgânico foi determinado por colorimetria e transformado em teor de matéria orgânica pela constante 1,724.

Os dados obtidos foram submetidos à Análise de Variância (ANOVA), com tratamentos inteiramente casualizados, com dois tratamentos e cinco repetições. Quando constatada a significância pelo teste $\mathrm{F}$, as médias foram comparadas pelo teste de Tukey a $5 \%$.

\section{RESULTADOS E DISCUSSÃO}

\section{Caracterização dos solos sob Savana e as Formações Florestais}

Os resultados obtidos indicam a clara influência dos solos na ocorrência dos fragmentos florestais em área de savana, na mesma linha de outros estudos com abordagens semelhantes, em outras regiões (TOPPA; MORENO et al. 2001; NERI et al., 2012). Estes observaram a existência de um gradiente de fertilidade controlando o gradiente fisionômico da vegetação.

Comparando-se os fragmentos florestais entre si, os solos com coloração avermelhada a amarelo-avermelhadas prevaleceram nas IF1 e IF2, enquanto nas IF3 e IF4 sobressaíram os solos com cores brunadas e amareladas. Enquanto nas Savanas, somente ocorrem solos com coloração brunada. Tal fato parece indicar um efeito do hidromorfismo, ou, pelo menos, da permanência de água mais prolongada sob savana e uma drenagem melhor sob floresta.

Quanto à granulometria, verificaram-se solos argilosos sob savana, com aumento de argila em profundidade, tanto nas ilhas florestais como nas savanas. Em geral são solos de textura média. Houve maior incremento de argila em profundidade nas florestas, ou seja, maior gradiente textural, o suficiente para classificar alguns perfis como Argissolos (com horizonte B textural) (Tabela 1).

Verificou-se uma tendência de solos com maiores teores de argila em superfície nas savanas e maior percentual de areia nos horizontes superficiais nas ilhas florestais, ao contrário do que observaram Martins et al. (2006) no estudo de gradiente de vegetação campestre a mata, na região de Humaitá (AM), com concentração de argila mais elevada em área de mata nativa, na camada de $0-20 \mathrm{~cm}$.

Os baixos valores de silte nos dois ambientes estudados e, consequentemente, a baixa relação silte/argila indica o avançado estágio de intemperismo dos solos sob savana em Roraima, corroborando com estudos de Melo et al. (2006) e Benedetti et al. (2011).

Quanto à densidade do solo, os resultados mostram uma tendência de aumento com a profundidade o que se deve, segundo Costa et al. (2003), a fatores como: teor reduzido de matéria orgânica, menor penetração de raízes, maior compactação ocasionada pelo peso dos horizontes sobrejacentes e diminuição da porosidade total 
TABELA 1: Valores médios dos parâmetros físicos dos solos sob os diferentes ambientes estudados.

TABLE 1: Mean values of soil physical parameters in different environments.

\begin{tabular}{ccccccccc}
\hline \multirow{2}{*}{$\begin{array}{c}\text { Cobertura } \\
\text { vegetal }\end{array}$} & \multirow{2}{*}{ Profundidade $(\mathrm{cm})$} & \multicolumn{3}{c}{ Umidade } & \multicolumn{3}{c}{ Granulometria $(\mathrm{dag} / \mathrm{kg})$} & \multirow{2}{*}{ R. P. } \\
\cline { 2 - 6 } IF1 & $0-10$ & 4,86 & 13,68 & 18,61 & 9,54 & 71,85 & 1,08 & 1,24 \\
& $10-20$ & 5,39 & 13,54 & 25,08 & 9,88 & 65,04 & 1,82 & 1,28 \\
& $20-40$ & 7,65 & 13,40 & 30,48 & 8,38 & 61,14 & 2,31 & 1,33 \\
SV1 & $0-10$ & 1,75 & 7,11 & 16,82 & 10,89 & 72,29 & 2,45 & 1,37 \\
& $10-20$ & 3,67 & 8,72 & 22,87 & 11,53 & 65,60 & 4,09 & 1,38 \\
& $20-40$ & 4,89 & 10,34 & 26,15 & 8,32 & 65,53 & 4,39 & 1,41 \\
IF2 & $0-10$ & 7,56 & 13,78 & 19,15 & 9,77 & 71,08 & 1,72 & 1,42 \\
& $10-20$ & 6,89 & 14,39 & 28,44 & 0,84 & 62,72 & 2,84 & 1,44 \\
& $20-40$ & 8,48 & 15,00 & 38,07 & 10,95 & 50,98 & 3,17 & 1,47 \\
SV2 & $0-10$ & 4,33 & 12,12 & 25,09 & 10,43 & 64,48 & 2,62 & 1,34 \\
& $10-20$ & 4,83 & 14,66 & 31,64 & 14,63 & 53,73 & 3,33 & 1,35 \\
& $20-40$ & 8,34 & 17,19 & 42,00 & 9,11 & 48,89 & 4,21 & 1,37 \\
IF3 & $0-10$ & 5,37 & 15,67 & 19,93 & 10,85 & 69,22 & 0,94 & 1,28 \\
& $10-20$ & 9,21 & 15,41 & 32,52 & 11,62 & 55,86 & 1,52 & 1,32 \\
& $20-40$ & 9,56 & 15,14 & 35,36 & 10,66 & 53,98 & 2,25 & 1,38 \\
SV3 & $0-10$ & 1,76 & 10,71 & 23,80 & 10,10 & 66,10 & 2,74 & 1,35 \\
& $10-20$ & 5,80 & 11,51 & 34,31 & 9,23 & 56,46 & 3,58 & 1,39 \\
& $20-40$ & 6,04 & 13,90 & 39,11 & 11,69 & 49,20 & 4,76 & 1,42 \\
IF4 & $0-10$ & 8,75 & 15,60 & 16,10 & 12,36 & 71,54 & 0,33 & 1,39 \\
& $10-20$ & 7,90 & 15,21 & 18,67 & 08,94 & 72,39 & 1,25 & 1,45 \\
& $20-40$ & 9,34 & 14,58 & 25,01 & 12,29 & 62,70 & 1,56 & 1,51 \\
SV4 & $0-10$ & 6,63 & 9,75 & 19,94 & 11,34 & 68,72 & 1,44 & 1,43 \\
& $10-20$ & 7,68 & 10,68 & 26,32 & 8,92 & 64,76 & 2,67 & 1,52 \\
& $20-40$ & 7,90 & 12,49 & 29,34 & 8,49 & 62,17 & 3,14 & 1,63 \\
\hline
\end{tabular}

Em que: U1 = umidade no período seco; U2 = umidade no período chuvoso; R.P. = resistência à penetração; Ds $=$ Densidade do solo.

devido à eluviação de argila. Os maiores valores foram obtidos nos solos sob savana, na profundidade em torno de $40 \mathrm{~cm}$. Nessa profundidade, em especial para classes dos Latossolos Amarelos Distróficos, coincide com caráter coeso, descrito por Benedetti et al. (2011), sendo estes solos classificados como Distrocoesos, conforme Embrapa (2013). A coesão não foi observada sob floresta.

Características morfológicas e físicas dos solos nos dois ambientes estudados indicam melhores condições de drenagem nos solos Florestais, podendo influenciar positivamente a ocorrência desta fitofisionomia, semelhante a estudos desenvolvidos por Martins et al. (2006) e Ferreira et al. (2002).

Foram verificados maiores valores de umidade nos solos sob as ilhas florestais, podendo estar associados ao microclima nestes ambientes florestais, resultados que tenderam a influenciar nos menores valores para a resistência a penetração.
Porém, os maiores valores da RP nos solos sob savana indicam o caráter coeso para as classes dos Latossolos e Argissolos Amarelos, já descrito por Benedetti et al. (2011), nas savanas de Roraima.

Analisando-se os dois ambientes (Tabela 2), quanto às características químicas, verifica-se que, em ambos os ecossistemas, os maiores teores de cálcio (Ca), soma de bases (SB), capacidade de troca de cátions total $(\mathrm{CTCt})$, capacidade de troca de cátions efetiva (CTCe), saturação por bases (V) e matéria orgânica do solo (MOS) concentram-se nos primeiros $10 \mathrm{~cm}$, resultado também encontrado por Rossi et al. (2005) e Campos et al. (2012). Valores mais elevados foram observados para os solos sob floresta, influenciando positivamente na diferenciação entre as fitofisionomias estudadas, resultado semelhante ao observado por Moreno e Schiavini (2001). Nas florestas, o horizonte superficial possui menor concentração de $\mathrm{Al}$ trocável e maiores teores de $\mathrm{P}$ disponível, $\mathrm{Ca}$ trocável e 
MOS, sendo possível que esses atributos tenham grande influência no estabelecimento das plântulas, favorecendo a sucessão florestal e manutenção das florestas em solos química e fisicamente um pouco melhores. Resultado similar foi reportado por Ruggiero et al. (2006).

Os valores para SB são significativamente superiores nos solos florestais, em todas as profundidades estudadas, em relação às savanas adjacentes, resultados corroborados por Martins et al. (2006), que obtiveram a mesma tendência em estudo de vegetação campestre e florestas adjacentes em Humaitá, no Estado do Amazonas.

Os solos são ácidos, com valores de $\mathrm{pH}\left(\mathrm{H}_{2} \mathrm{O}\right)$ na profundidade $0-10 \mathrm{~cm}$ sem diferença estatística, mas, na profundidade de $10-20 \mathrm{~cm}$, os valores se mostraram significativamente diferentes. Nos horizontes diagnósticos, os valores se aproximam dos encontrados por Melo et al. (2006) na região do Apiaú - RR. Nas áreas de savana, resultados semelhantes foram verificados por Benedetti et al. (2011), no campus do Cauamé - UFRR.

Analisando-se os teores de K, verifica-se que os valores diferiram significativamente entre os dois ambientes em todas as profundidades estudadas, com os maiores valores sob floresta, devido tanto à ciclagem quanto a menores perdas por erosão.

Nos primeiros $10 \mathrm{~cm}$, os teores de P foram baixos, mas com tendência de melhores condições químicas sob floresta, sendo um dos fatores mais limitantes ao desenvolvimento da vegetação na região amazônica. Os valores são um pouco acima dos observados na região por Martins et al. (2006), em especial nas áreas sob floresta. Nestes ambientes da Amazônia, de uma forma geral, a dinâmica do fósforo é dependente da ciclagem da matéria orgânica, consistente com a ligeira relação entre os teores de $\mathrm{P}$ e os teores de MOS. A ciclagem eficiente e a habilidade da comunidade vegetal em conviver com baixas concentrações de P revelam o trade-off que garante a estabilidade das florestas nestes solos pobres.

O teor de MOS foi maior nos solos florestas, concentrando-se no horizonte superficial, resultado semelhante aos verificados por Moreno e Schiavini (2001) Araújo et al. (2004), Barbosa e Ferreira (2004) e Ruivo et al. (2002). Com maiores valores de MOS, verificaram-se níveis mais elevados de nutrientes em superfície, evidenciando a dependência da CTC em relação à matéria orgânica, o que se coaduna com resultados encontrados por Rossi et al. (2005), em estudo de Floresta Estacional Semidecidual no Estado de São Paulo.

Na floresta, o acúmulo de MOS é maior que nos solos sob savana, provavelmente, em função da maior biomassa vegetal e de raízes, considerando as condições de clima regional. Este processo é retroalimentado, ou seja, pode-se argumentar que as características desse ambiente são favorecidas pela

TABELA 2: Valores médios de atributos químicos em solos sob fragmentos florestais (IF) e savana (sv) em três profundidades.

TABLE 2: Mean values of chemical atributos in soils under forest and savanna at three depths.

\begin{tabular}{|c|c|c|c|c|c|c|}
\hline \multirow{3}{*}{ Atributos químicos } & IF1 & SV1 & IF2 & SV2 & IF3 & SV3 \\
\hline & \multicolumn{6}{|c|}{ Profundidade $(\mathrm{cm})$} \\
\hline & $0-10$ & $0-10$ & $10-20$ & $10-20$ & $20-40$ & $20-40$ \\
\hline $\mathrm{pH}\left(\mathrm{H}_{2} \mathrm{O}\right)$ & $5,71 \mathrm{a}$ & $5,48 \mathrm{a}$ & $5,53 \mathrm{a}$ & $5,15 b$ & $5,65 \mathrm{a}$ & $5,30 \mathrm{~b}$ \\
\hline $\mathrm{Ca}^{2+}\left(\mathrm{cmol}_{\mathrm{c}} / \mathrm{dm}^{3}\right)$ & $3,29 \mathrm{a}$ & $1,13 \mathrm{~b}$ & $1,56 \mathrm{a}$ & $0,61 \mathrm{~b}$ & $5,65 \mathrm{a}$ & $0,46 \mathrm{~b}$ \\
\hline $\mathrm{Mg}^{2+}\left(\mathrm{cmol}_{\mathrm{c}} / \mathrm{dm}^{3}\right)$ & $0,88 \mathrm{a}$ & $0,43 \mathrm{~b}$ & $0,56 \mathrm{a}$ & $0,19 b$ & $0,56 \mathrm{a}$ & $0.18 \mathrm{~b}$ \\
\hline $\mathrm{K}^{+}\left(\mathrm{cmol}_{\mathrm{c}} / \mathrm{dm}^{3}\right)$ & $0,13 \mathrm{a}$ & $0,05 \mathrm{~b}$ & $0,06 \mathrm{a}$ & $0,02 \mathrm{~b}$ & $0,04 \mathrm{a}$ & $0,02 \mathrm{~b}$ \\
\hline $\mathrm{Al}^{3+}\left(\mathrm{cmol}_{\mathrm{c}} / \mathrm{dm}^{3}\right)$ & $0,11 \mathrm{~b}$ & $0,37 \mathrm{a}$ & $0,56 \mathrm{~b}$ & $0,62 \mathrm{a}$ & $0,20 \mathrm{a}$ & $0,48 \mathrm{a}$ \\
\hline $\mathrm{H}+\mathrm{Al}\left(\mathrm{cmol}_{\mathrm{c}} / \mathrm{dm}^{3}\right)$ & $4,02 \mathrm{a}$ & $3,82 \mathrm{a}$ & $3,32 \mathrm{a}$ & $3,94 \mathrm{a}$ & $2,26 \mathrm{~b}$ & $3,10 \mathrm{a}$ \\
\hline $\mathrm{P}\left(\mathrm{mg} / \mathrm{dm}^{3}\right)$ & $6,59 \mathrm{a}$ & $2,75 \mathrm{~b}$ & $3,51 \mathrm{a}$ & $0,53 \mathrm{~b}$ & $1,26 \mathrm{a}$ & $0,23 \mathrm{~b}$ \\
\hline $\mathrm{SB}\left(\mathrm{cmol}_{\mathrm{c}} / \mathrm{dm}^{3}\right)$ & $4,30 \mathrm{a}$ & $1,61 \mathrm{~b}$ & $2,17 \mathrm{a}$ & $0,82 \mathrm{~b}$ & $1,73 \mathrm{a}$ & $0,65 \mathrm{~b}$ \\
\hline $\operatorname{CTCt}\left(\mathrm{cmol}_{\mathrm{c}} / \mathrm{dm}^{3}\right)$ & $8,36 \mathrm{a}$ & $5,43 \mathrm{~b}$ & $5,45 \mathrm{a}$ & $4,53 \mathrm{a}$ & $4,12 \mathrm{a}$ & $3,76 \mathrm{a}$ \\
\hline $\operatorname{CTCe}\left(\mathrm{cmol}_{\mathrm{c}} / \mathrm{dm}^{3}\right)$ & $4,41 \mathrm{a}$ & $1,98 \mathrm{~b}$ & $2,35 \mathrm{a}$ & $1,46 \mathrm{~b}$ & $1,94 \mathrm{a}$ & $1,14 \mathrm{~b}$ \\
\hline $\mathrm{V}(\%)$ & $50,29 a$ & $28,17 \mathrm{~b}$ & $39,78 \mathrm{a}$ & $16,11 \mathrm{~b}$ & $40,98 \mathrm{a}$ & $16,80 \mathrm{~b}$ \\
\hline $\mathrm{m}(\%)$ & $3,96 \mathrm{~b}$ & $26,49 \mathrm{a}$ & $9,83 \mathrm{~b}$ & $46,58 \mathrm{a}$ & $11,79 \mathrm{~b}$ & $39,46 \mathrm{a}$ \\
\hline $\operatorname{MOS}\left(\mathrm{g} / \mathrm{kg}^{-1}\right)$ & $31,14 \mathrm{a}$ & $18,52 \mathrm{~b}$ & $14,93 \mathrm{a}$ & $13,05 \mathrm{a}$ & $7,86 \mathrm{a}$ & $7,91 \mathrm{a}$ \\
\hline
\end{tabular}

Em que: $\mathrm{P}=$ Fósforo disponível; $\mathrm{SB}=$ Soma de bases; $\mathrm{CTCt}=$ Capacidade de troca catiônica total; $\mathrm{CTCe}=$ Capacidade de troca catiônica efetiva; $\mathrm{V}$ = Saturação por bases; $\mathrm{m}$ = Saturação por alumínio; MOS = Matéria orgânica do solo. 
ciclagem.

Em geral, os valores obtidos para $\mathrm{Al}^{3+} \mathrm{e}$ saturação por alumínio (m) estão bem inferiores aos normalmente encontrados na região por diversos autores (MELO et al., 2006; BENEDETTI et al., 2011), mesmo em áreas de florestas, sendo significativamente superiores na savana, nas profundidades de $0-10 \mathrm{~cm}$ e de $10-20 \mathrm{~cm}$. Tais resultados convergem aos encontrados nos estudos de Moreno e Schiavini (2001), confirmando neste caso, a teoria do oligotrofismo relatada por Alvin (1954), que considera a presença do alumínio tóxico como fator ecológico de grande efeito sobre a ocorrência da vegetação de cerrados (no caso, das savanas de Roraima).

A condição de baixa fertilidade natural na área é resultante da influência do material de origem pré-intemperizado da Formação Boa Vista (Pliopleistoceno) e, também, em função das condições climáticas da região, de acentuado intemperismo atual. Os baixos níveis de fertilidade dos solos sob savana foram registrados em vários estudos na região (SCHAEFER et al., 1993; SCHAEFER, 1997; ROSSI et al., 2005; BARROS et al., 2009; BENEDETTI et al., 2011). Segundo Schaefer (1997), contudo, boa parte das ilhas florestais em Roraima se assenta sobre solos mais vermelhos, derivados de rochas graníticognáissicas ou máficas, resultando em solos física e quimicamente melhores que aqueles formados dos sedimentos Boa Vista. No presente estudo, entretanto, solos semelhantes ocorrem tanto sob savana quanto floresta, embora com sutis diferenças morfológicas, físicas e químicas entre os dois ambientes.

\section{Relações Solos e Ambientes de Savana e Formações Florestais}

A área estudada é de domínio das

TABELA 3: Classes de solos sob os diferentes ambientes estudados.

TABLE 3: Soils under different environments.

\begin{tabular}{|c|c|c|c|c|}
\hline & \multicolumn{4}{|c|}{ Floresta Estacional Semidecidual } \\
\hline & 1 & 2 & 3 & 4 \\
\hline \multirow{4}{*}{ Solos } & $\begin{array}{c}\text { ARGISSOLO } \\
\text { AMARELO } \\
\text { Distrocoeso (PAdx) }\end{array}$ & $\begin{array}{l}\text { PLINTOSSOLO } \\
\text { PETRICO } \\
\text { Concrecionário } \\
\text { argissólico (FFc) }\end{array}$ & $\begin{array}{c}\text { PLINTOSSOLO } \\
\text { PETRICO } \\
\text { Concrecionário típico } \\
\text { (FFc) }\end{array}$ & $\begin{array}{c}\text { LATOSSOLO } \\
\text { AMARELO Distrocoeso } \\
\text { (LAdx) }\end{array}$ \\
\hline & $\begin{array}{c}\text { LATOSSOLO } \\
\text { AMARELO } \\
\text { Distrocoeso (LAdx) }\end{array}$ & $\begin{array}{l}\text { LATOSSOLO } \\
\text { VERMELHO- } \\
\text { AMARELO } \\
\text { Distrófico (LVA) } \\
\text { / LATOSSOLO } \\
\text { VERMELHO } \\
\text { Distrófico (LVd) }\end{array}$ & $\begin{array}{c}\text { LATOSSOLO } \\
\text { VERMELHO- } \\
\text { AMARELO Distrófico } \\
\text { (LVAd) }\end{array}$ & $\begin{array}{c}\text { ARGISSOLO } \\
\text { AMARELO Distrocoeso } \\
\text { (PAdx })\end{array}$ \\
\hline & \multicolumn{4}{|c|}{ Savana Gramíneo-Lenhosa } \\
\hline & 1 & 2 & 3 & 4 \\
\hline \multirow[t]{2}{*}{ Solos } & $\begin{array}{c}\text { ARGISSOLO } \\
\text { AMARELO } \\
\text { Distrocoeso } \\
\text { (PAd) associado } \\
\text { a ARGISSOLO } \\
\text { ACINZENTADO } \\
\text { Distrocoeso abrúptico } \\
\text { dúrico (PACdx) }\end{array}$ & $\begin{array}{l}\text { LATOSSOLO } \\
\text { VERMELHO- } \\
\text { AMARELO } \\
\text { Distrófico (LVAd) }\end{array}$ & $\begin{array}{c}\text { PLINTOSSOLO } \\
\text { PETRICO } \\
\text { Concrecionário típico } \\
\text { (FFc) }\end{array}$ & $\begin{array}{c}\text { ARGISSOLO } \\
\text { AMARELO Distrocoeso } \\
\text { (PAd) }\end{array}$ \\
\hline & $\begin{array}{c}\text { LATOSSOLO } \\
\text { AMARELO } \\
\text { Distrocoeso (LAdx) }\end{array}$ & $\begin{array}{c}\text { ARGISSOLO } \\
\text { AMARELO } \\
\text { Distrocoeso (PAdx) }\end{array}$ & $\begin{array}{c}\text { LATOSSOLO } \\
\text { VERMELHO- } \\
\text { AMARELO Distrófico } \\
\text { (LVAd) }\end{array}$ & $\begin{array}{c}\text { LATOSSOLO } \\
\text { AMARELO Distrocoeso } \\
\text { (LAdx) / GLEISSOLO } \\
\text { HÁPLICO Tb Distrófico } \\
\text { plíntico }(\mathrm{GXb})\end{array}$ \\
\hline
\end{tabular}


Savanas associadas a solos originados a partir de sedimentos pré-intemperizados argiloarenosos da Formação Boa Vista, datados do Pliopleistoceno (BARROS et al., 2009; BENEDETTI et al., 2011), dominada por solos com horizontes Bw, Bt e com menor área ocupada $\mathrm{Bf}$ e $\mathrm{Btf}$, representados pelo Latossolo Amarelo Distrocoeso (LAdx), Argissolo Amarelo Distrocoeso (PAdx), Latossolo VermelhoAmarelo Distrófico (LVAd), Plintossolo Pétrico Concrecionário $(\mathrm{FFc})$, Argissolo Acinzentado Distrófico (PACdx) e Gleissolo Háplico Tb Distrófico (GXbd). Em contraste abrupto com essa fitofisionomia savânica, nas ilhas de Floresta Estacional Semidecidual ocorrem as mesmas classes de solo, diferindo apenas na presença de solos mais vermelhos (Latossolo Vermelho Distrófico, LVd), conforme Embrapa (2013) (Tabela 3).

Nos fragmentos florestais IF2 e IF3 foram caracterizados Plintossolos Pétricos Concrecionários e, em especial, em IF2, de maior diversidade pedológica, com Plintossolos Pétricos Concrecionários dominantes, seguidos dos Latossolos Vermelho-Amarelos Distróficos e Latossolo Vermelho Distrófico. As duas últimas classes de solos estão associadas à influência de rocha Basáltica da Formação Apoteri ou a rochas cristalinas que afloram nas proximidades.

Quanto ao relevo, observa-se que todos os ambientes estão posicionados em relevo plano, com declividade entre 0 a $3 \%$, porém, a IF2 está inserida em área de relevo suave ondulado, destacando-se o fragmento em cota mais elevada. O relevo exerce forte controle na dinâmica da água na região, observando-se que os solos bem drenados estão posicionados em relevo plano a suave ondulado com altitude em torno de $80 \mathrm{~m}$, cuja coloração dominante varia de amarelada a avermelhada, enquanto solos com drenagem pior, e mesmo características Hidromórficas, ocupam as áreas baixas ou abaciadas da paisagem, com cores que indicam algum grau de redução temporária (Tabela 4).

$\mathrm{Na}$ comparação de ambientes, podese verificar que a classe de solo não é um fator determinante na ocorrência de florestas na região de savana de Roraima, pois em um mesmo fragmento foram identificados tanto solos bem diferentes da savana do entorno, quanto em outros fragmentos, as classes não diferiram. Esse resultado concorda com o estudo de Ruggiero et al. (2006), em fragmentos nas Savanas do Brasil central.

TABELA 4: Unidades geoambientais na Região de estudo.

TABLE 4: Geoenvironmental units in the studied region.

\begin{tabular}{|c|c|c|c|c|c|c|}
\hline $\begin{array}{l}\text { Cobertura } \\
\text { vegetal }\end{array}$ & Geologia & Geomorfologia & Solos & Vegetação & $\begin{array}{c}\text { Clima } \\
\text { (Köppen) }\end{array}$ & Tempo \\
\hline IF1 & $\begin{array}{c}\text { Formação Boa } \\
\text { Vista }\end{array}$ & $\begin{array}{c}\text { Plano, com } \\
\text { declividade entre } \\
0 \text { e } 3 \%\end{array}$ & $\begin{array}{c}\text { PAd associado } \\
\text { a LAd }\end{array}$ & $\begin{array}{c}\text { Floresta } \\
\text { Estacional } \\
\text { Semidecidual }\end{array}$ & Aw & $\begin{array}{l}\text { Colúvio do } \\
\text { Pliopleistoceno }\end{array}$ \\
\hline IF2 & $\begin{array}{l}\text { Formação Boa } \\
\text { Vista e influência } \\
\text { de produtos do } \\
\text { intemperismo } \\
\text { do Basalto } \\
\text { da Formação } \\
\text { Apoteri. }\end{array}$ & $\begin{array}{c}\text { Relevo suave } \\
\text { ondulado, com } \\
\text { declividade entre } \\
3 \text { e } 8 \% .\end{array}$ & $\begin{array}{c}\text { FFc associados } \\
\text { a LVA e LV }\end{array}$ & $\begin{array}{c}\text { Floresta } \\
\text { Estacional } \\
\text { Semidecidual }\end{array}$ & Aw & $\begin{array}{l}\text { Jurássico/ } \\
\text { Cretáceo }\end{array}$ \\
\hline IF3 & $\begin{array}{l}\text { Formação Boa } \\
\text { Vista }\end{array}$ & $\begin{array}{c}\text { Plano, com } \\
\text { declividade entre } \\
0 \text { e } 3 \%\end{array}$ & $\begin{array}{l}\text { FFc associado } \\
\text { a LAd e PAd }\end{array}$ & $\begin{array}{c}\text { Floresta } \\
\text { Estacional } \\
\text { Semidecidual }\end{array}$ & Aw & Pliopleistoceno \\
\hline IF4 & $\begin{array}{c}\text { Formação Boa } \\
\text { Vista }\end{array}$ & $\begin{array}{c}\text { Plano, com } \\
\text { declividade entre } \\
0 \text { e } 3 \%\end{array}$ & $\begin{array}{c}\text { LAd associado } \\
\text { a PAd }\end{array}$ & $\begin{array}{c}\text { Floresta } \\
\text { Estacional } \\
\text { Semidecidual }\end{array}$ & Aw & Pliopleistoceno \\
\hline SV & $\begin{array}{c}\text { Formação Boa } \\
\text { Vista }\end{array}$ & $\begin{array}{c}\text { Plano, com } \\
\text { declividade entre } \\
0 \text { e } 3 \%\end{array}$ & $\begin{array}{l}\text { LAd, PAd, } \\
\text { PACdx } \\
\text { Associados a } \\
\text { FFc e GXb }\end{array}$ & $\begin{array}{l}\text { Savanas } \\
\text { Gramíneo- } \\
\text { lenhosa }\end{array}$ & Aw & Pliopleistoceno \\
\hline
\end{tabular}

Em que: IF1 - Ilha Florestal 1; IF2 - Ilha Florestal 2; IF3 - Ilha Florestal 3; IF4 - Ilha Florestal IF4; SV - Savana. 
Nos fragmentos florestais, foi possível verificar a presença marcante de caráter petroplíntico, em profundidade variável, satisfazendo em alguns casos a posição diagnóstica para Plintossolo. Na maioria dos Latossolos descritos, contudo, esse caráter posicionava-se além dos $150 \mathrm{~cm}$ de profundidade e até mesmo fora da seção de controle para essa classe, conforme Embrapa (2013).

Em geral, os FFc estão posicionados em relevos ondulado e suave ondulado, com abundantes concreções ferruginosas (petroplintitas e litoplintitas), conhecidas pelas etnias indígenas da região como Cabeça de Jacaré, Canga Laterítica, Pedra Marará, conforme descritos por diversos autores em trabalhos realizados na região (MELO et al., 2006; VALE JÚNIOR et al., 2007; BENEDETTI et al., 2011). Esse processo de plintização pode ter ocorrido em função de oscilações climáticas ocorridas na região (condições paleoclimáticas), conforme modelo de evolução da paisagem (RANZI, 1993). Dentro de uma mesma região climática, o pedoclima (clima do solo) pode variar em função de características físicas dos solos, como estrutura, textura, porosidade, capacidade de retenção hídrica, entre outras (RESENDE et al., 1992). No presente estudo, observaram-se diferenças pedológicas entre solos sob floresta e savana, com tendência a solos mais vermelhos nos fragmentos florestais, o que revela uma possível influência do material de origem. Tal é o caso de IF2, nas proximidades do afloramento de basalto da Serra de Nova Olinda, ou de IF3, no qual os solos são provenientes de decomposição da canga, sempre com cores mais vermelhas.

.Analisando-se isoladamente os Latossolos descritos no fragmento florestal IF2, com ênfase na presença e profundidade do caráter petroplíntico, é possível perceber que os Plintossolo Pétricos concrecionários estão sofrendo processo de Latolização. Postula-se que em climática mais seca no Quaternário houve intenso processo de couraçamento e formação de petroplintita, seguida da instalação de um clima mais úmido, quando este processo foi substituído por intenso intemperismo e degradação da canga previamente formada.

Baseando-se na caracterização climática da região (BARBOSA et al., 1997), todos os ambientes estudados se encontram sob um mesmo clima atual (Aw de Köppen), com precipitações pluviométricas em torno de $1.500 \mathrm{~mm} /$ ano e temperatura média anual em torno de $25^{\circ} \mathrm{C}$.

Verifica-se que tanto os fragmentos florestais como as savanas estão sob as mesmas condições geomorfológicas (Pediplano Rio Branco), mas possuem diferenças pedológicas e de material de origem que exercem notável efeito na cobertura vegetal. Não se pode deixar, contudo, de aventar possíveis mudanças climáticas que explicam os avanços e retrações dos espações florestais da Amazônia.

Assim, permanece uma hipótese plausível a ser testada, que tais fragmentos isolados representem um paleoespaço outrora mais amplo, florestado e que os remanescentes atuais que ocorrem em mosaico dentro da savana, sejam

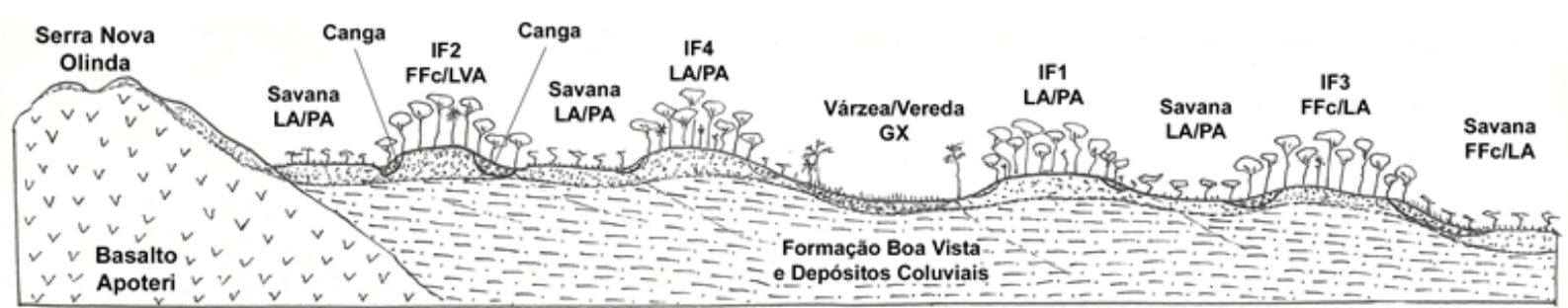

FIGURA 1: Topossequência representando as áreas de estudo, partindo da Serra de Nova Olinda (Afloramento de Basalto da Formação Apoteri), seguida da Ilha florestal IF2 e no final a IF3. SV - savana; IF1 - Ilha Florestal 1; IF2 - Ilha Florestal 2; IF3 - Ilha Florestal 3; IF4 Ilha Florestal 4. LA - Latossolo Amarelo; PA - Argissolo Amarelo; FFc - Plintossolo Pétrico concrecionário típico; LVA - Latossolo Vermelho-Amarelo; GX - Gleissolo.

FIGURE 1: Toposequence representing the studied areas, from the Nova Olinda Hills (Basalt Outcrop of the Apoteri Formation), next Island forest IF2 and IF3 in the end. SV - savanna; IF1 - Island Forest 1; IF2 - Island Forest 2; IF3 - Island Forest 3; IF4 - Island Forest 4. LA - Oxisol; PA Ultisol; FFc - Ultisol; LVA - Oxisol; GX - Entisol. 
núcleos nos quais os solos, sutilmente diferenciados em relação à savana circundante, permitiram a sucessão florestal e estabilidade ecológica, em um novo quadro climático. Ressalta-se que a tendência ecológica atual em Roraima, já intensamente descrita em alguns estudos (e.g. SCHAEFER, 1997), é de invasão florestal em áreas de savana, através da dissecação fluvial e captura de veredas de buritis.

Nas transições climáticas seco-úmidas, ou vice-versa, os solos devem ter desempenhado um papel tamponante (buffering) e relevante na distribuição das savanas e florestas em Roraima, ora selecionando espécies mais tolerantes à seca e ao fogo, ora exercendo uma pressão seletiva favorecendo a invasão de espécies florestais, nas quais fatores físico-químicos combinam, contribuíram para o estabelecimento e adaptação de ecossistemas florestais. Dentro de um espaço ecotonal, como no Nordeste de Roraima, é esperado um mosaico de fragmentos florestais, em que o quadro dinâmico segue indefinido e sujeito a perturbações, inclusive antrópicas.

\section{CONCLUSÕES}

Atributos dos solos, mas não a classe taxonômica, são fatores que explicam o equilíbrio dinâmico entre a Floresta e a Savana no Nordeste de Roraima.

Nos gradientes de floresta-savana estudados, a classe dos Latossolos foi predominante em área ocupada, seguido de Argissolos e Plintossolos;

Nos fragmentos florestais prevaleceram os solos com colorações avermelhadas e amareloavermelhadas, com pouca expressão de cores amarelas. Já nos solos sob Savanas, os solos com coloração amarelo-brunada foram predominantes;

A ocorrência dos fragmentos florestais nas áreas de savana não é explicada pela classe de solo. Embora os solos sejam todos distróficos, há melhores condições físico-químicas, com maiores teores de fósforo disponível e matéria orgânica, menores valores de $\mathrm{pH}$ e alumínio trocável, nos solos sob floresta; além disso, estes solos possuem menor densidade do solo, menor resistência à penetração e maiores percentuais de umidade;

Oscilações paleoclimáticas podem auxiliar na compreensão da expansão e retração dos espaços florestados em Roraima, mas não é necessário invocar qualquer condição paleoclimática para explicar a ocorrência atual de fragmentos de floresta isolados na savana, pois há um conjunto robusto de características diferenciadas de solos entre os dois extremos de vegetação, representando um equilíbrio dinâmico em um clássico espaço ecotonal.

\section{AGRADECIMENTOS}

À Pró-Reitoria de Pesquisa e PósGraduação, responsável pelo Programa de PósGraduação em Recursos Naturais da Universidade Federal de Roraima e à Embrapa Roraima.

\section{REFERÊNCIAS BIBLIOGRÁFICAS}

ALVIN, P. de T.; ARAÚJO, W. A. O solo como fator ecológico no desenvolvimento da vegetação no Centro-Oeste do Brasil. Boletim Geográfico, Rio de Janeiro, v. 11, p. 569-578. 1954.

ARAÚJO, E. A. et al. Uso da terra e propriedades físicas e químicas de Argissolo Amarelo distrófico na Amazônia Ocidental. Revista Brasileira de Ciência do Solo, Viçosa, v. 28, p. 307-315, 2004.

BARBOSA, R. I. Distribuição das chuvas em Roraima. In: BARBOSA, R. I.; FERREIRA, E. J. G.; CASTELlON, E. G. Homem, Ambiente e Ecologia no Estado de Roraima. Manaus: Instituto Nacional de Pesquisas da Amazônia, p. 325-335. 1997.

BARBOSA, R.I.; CAMPOS, C. Detection and geographical distribution of clearing areas in the savannas ('lavrado') of Roraima using Google Earth web tool. Journal of. Geography and Regional Planning, v. 4, n. 3, p. 122-136. 2011.

BARBOSA, R.I.; FERREIRA, C.A.C. Biomassa acima do solo de um ecossistema de "campina" em Roraima, norte da Amazônia brasileira. Acta Amazônica, Manaus, v. 34, n. 4, p. 577-586. 2004.

BARROS, L. da S. et al. Perdas de solo e água em plantio de Acacia mangium wild e savana em Roraima, norte da Amazônia. Revista Brasileira de Ciência do Solo, Viçosa, v. 33, p. 447- 454. 2009. BENEDETTI, U.G. et al. Gênese, química e mineralogia de solos derivados de sedimentos pliopleistocênicos e de rochas vulcânicas básicas em Roraima, Norte Amazônico. Revista Brasileira de Ciência do Solo, Viçosa, v. 35, p. 299-312. 2011.

CAMPOS, M. C. C. et al. Topossequência de solos 
na transição Campos Naturais-Floresta na região de Humaitá, Amazonas. Acta Amazônica, Manaus, v. 42, n. 3, p. 387-398. 2012.

COSTA, A. M. et al. Influência da cobertura vegetal na densidade de três solos da cerrado. In: II Simpósio Regional de Geografia. Anais... Uberlândia: 2003. EMBRAPA. Centro Nacional de Pesquisa de Solos. Manual de métodos de análise de solos. 2. ed. rev. e atual. Rio de Janeiro: EMBRAPA, 1997. 212 p. EMBRAPA. Sistema Brasileiro de Classificação do Solos. 3. ed. Rio de Janeiro: Embrapa Solos, 2013. 306 p.

FELFILI, J. M. et al. Floristic composition and community structure of a seasonally deciduous forest on limestone outcrops in Central Brazil. Revista Brasileira de Botânica, v. 30, n. 4, p. 611621. 2007.

FERREIRA, S. J. F. et al. Propriedades físicas do solo após extração seletiva de madeira na Amazônia Central. Acta Amazônica, Manaus, v. 32, n. 3, p. 449-466. 2002.

HAFFER, J. 1974. Avian Speciation Tropical South America. Publication of the Nutall Ornitological Clib. Cambridge: 1974. 390 p.

HUBER, O. et al. Flora and vegetation of the Venezuelan Llanos: a review. In: PENNINGTON, R. T.; LEWIS, G. P.; RATTER, J. A. (eds.). Neotropical Savannas and Seasonally Dry Forests: Plant Diversity, Biogeography, and Conservation. Oxford: Taylor \& Francis Group, Boca Raton, 2006. P. 95-120.

LAURANCE, W. F.; VASCONCELOS, H. L.; LOVEJOY, T. E. Forest loss and fragmentation in the Amazon: implications for wildlife conservation. Oryx, Cambridge, v. 34, n. 1, p. 39-45. 2000.

MARTINS, G. C. et al. Campos nativos e matas adjacentes da região de Humaitá (AM): atributos diferenciais dos solos. Ciência e Agrotecnologia, Lavras, v. 30, p. 221-227. 2006.

MAYLE, F. E.; POWER, M. J. Impact of a drier 520 Early-Mid-Holocene climate upon Amazonian forests. Philosophical Transactions of the Royal Society B, v. 363: p. 1829-1838. 2008.

MELO, V. F. et al. Caracterização física, química e mineralógica de solos da Colônia Agrícola do Apiaú (Roraima, Amazônia) sob diferentes usos e após queima. Revista Brasileira de Ciências do Solo, v. 30, p. 1039-1050. 2006.

MIRANDA, I. S.; ABSY, M. L.; REBELO, G. H. Community structure of woody plants of Roraima savannahs, Brazil. Plant Ecology, Netherlands, v. 164, p. 109-123. 2003.
MORENO, M. I. C.; SCHIAVINI. I. Relação entre vegetação e o solo em um gradiente florestal na Estação Ecológica do Panga, Uberlândia (MG). Revista Brasileira de Botânica, v. 24, p. 537-544. 2001.

MUNSELL COLOR. Munsell soil color charts. GretagMacbeth, New Windsor, New York, USA, 2009.

NERI, A. V. et al. The influence of soils on the floristic composition and community structure of an area of Brazilian Cerrado vegetation. Edinburgh Journal of Botany, v. 69, n. 1, p. 1-27, 2012.

OLIVEIRA-FILHO, A. T.; JARENKOW, J. A.; RODAL, M. J. N. Floristic relationships of seasonally dry forests of Eastern South America based on tree species distribution patterns. In: PENNINGTON, R. T.; LEWIS, G. P.; RATTER, J. A. (eds.). Neotropical Savannas and Seasonally Dry Forests: Plant Diversity, Biogeography, and Conservation. Oxford: Taylor \& Francis Group, Boca Raton, 2006. P. 159-192

RANZI, A. A paleofauna da Amazônia indica áreas de pastagem com pouca cobertura vegetal. Ciência Hoje, v. 16, p. 48-51. 1993.

RIBEIRO, J. F.; WALTER, B. M. T. As principais fitofisionomias do Bioma Cerrado. In: SANO, S. M; ALMEIDA, S. P. RIBEIRO, J. F. (eds.). Cerrado: ecologia e flora. Brasilia: Embrapa Cerrado, 2008. P. 152-212.

RESENDE, M.; CARVALHO FILHO, A.; LANI, J. L. Características do solo e da paisagem que influenciam a susceptibilidade a erosão, 1992.

ROSS, K. A.; FOX, B. J.; MARILYN, D. Changes to plant species richness in forest fragments: fragment age, disturbance and fire history may be as important as area. Journal of Biogeography, Malden, v. 29, p. 749-765. 2002.

ROSSI, M. et al. Relação solo/vegetação em área natural no parque estadual de Porto Ferreira. Revista do Instituto Florestal, v. 17, p. 45-61. 2005.

RUGGIERO, P. G. C. et al. Relação entre solo, vegetação e topografia em área de cerrado (Parque Estadual de Vassununga, SP): como se expressa em mapeamentos? Acta Botânica. Brasília, v. 20, p. 383-394. 2006.

RUIVO, M. L. P. et al. Os solos de uma topossequêcia na ilha de Algodoal/Maiandeua, Nordeste do Estado do Pará, Brasil: Composição química e produção de Matéria Orgânica. Acta Amazônica, Manaus, v. 32, n. 2, p. 257-266. 2002.

SANTOS, R. D. dos et al. Manual de descrição e 
coleta de solo no campo. 5. ed. Viçosa: Sociedade Brasileira da Ciência do Solo. 100 p.

SCHAEFER, C.E.G.R. Ecogeography and human scenario in Northeast Roraima, Brazil. Ci. Cult., 49:241-252, 1997.

SCHAEFER, C.E.G.R. \& DALRYMPLE， J. Landscape evolution in Roraima, North Amazonia, Planation, paleosols and paleoclimates. Zeit. Geomorph, 39:1-28.,1995.

TOPPA, R. H. Estrutura e diversidade florística das diferentes fisionomias de Cerrado e suas correlações com o solo na Estação Ecológica de Jataí, Luis Antônio, SP. 127 p. Tese de Doutorado, Universidade Federal de São Carlos. São Paulo. 2004.

VALE JÚNIOR, J. F.; SCHAEFER, C. G. R.; COSTA, J. A. Transferência de conhecimento: diálogos entre os saberes indígena e técnico na Terra Indígena Malacacheta, Roraima. Revista Brasileira de Ciência do Solo, Viçosa, v. 31, p. 403-412. 2007. 